\title{
A comparison of work-exacerbated asthma cases from clinical and epidemiological settings
}

\author{
Paul K Henneberger MPH ScD ${ }^{1}$, Xiaoming Liang MS ${ }^{1}$, Catherine Lemière MD MSc ${ }^{2}$
}

PK Henneberger, X Liang, C Lemière. A comparison of workexacerbated asthma cases from clinical and epidemiological settings. Can Respir J 2013;20(3):159-164.

BACKGROUND: Clinical and epidemiological studies commonly use different case definitions in different settings when investigating workexacerbated asthma (WEA). These differences are likely to impact characteristics of the resulting WEA cases.

OBJECTIVES: To investigate this issue by comparing two groups of WEA cases, one identified using an intensive clinical evaluation and another that fulfilled epidemiological criteria.

METHODS: A total of 53 clinical WEA cases had been referred for suspected work-related asthma to two tertiary clinics in Canada, where patients completed tests that confirmed asthma and ruled out asthma caused by work. Forty-seven epidemiological WEA cases were employed asthma patients treated at a health maintenance organization in the United States who completed a questionnaire and spirometry, and fulfilled criteria for WEA based on self-reported, work-related worsening of asthma and relevant workplace exposures as judged by an expert panel.

RESULTS: Using different case criteria in different settings resulted in case groups that had a mix of similarities and differences. The clinical WEA cases were more likely to have visited a doctor's office $\geq 3$ times for asthma in the past year (75\% versus $11 \%$; $\mathrm{P}<0.0001)$, but did not seek more asthma-related emergency or in-patient care, or have lower spirometry values. The two groups differed substantially according to the industries and occupations where the cases worked.

CONCLUSIONS: Findings from both types of studies should be considered when measuring the contribution of work to asthma exacerbations, identifying putative agents, and selecting industries and occupations in which to implement screening and surveillance programs.

Key Words: Asthma; Asthma exacerbation; Case criteria; Work-related asthma

\footnotetext{
A sthma is considered to be 'work-related' when a relationship between the symptoms of asthma and the workplace is present. Work-related asthma (WRA) encompasses two major categories: first, occupational asthma $(\mathrm{OA})$ is caused by work and subdivided into sensitizer-induced $\mathrm{OA}$ and irritant-induced OA (1); second, workexacerbated asthma (WEA) refers to pre-existing asthma or concurrent (or coincident) asthma that is exacerbated by a workplace-related stimulus (2). Concurrent or coincident asthma refers to a case with onset that occurs during employment but is unrelated to workplace conditions. Professional organizations, such as the American Thoracic Society (3) and the American College of Chest Physicians (1), have published recommended criteria for diagnosing WRA. In practice, clinicians and researchers use a variety of criteria for WRA.

In clinical settings, WRA case definitions are influenced by local standards of care and medicolegal definitions for workers' compensation benefits. Objective tests, such as serial peak-expiratory flow and methacholine challenge, at work and away from work are commonly used to evaluate potential cases of WRA $(4,5)$. In selected locations, such as Quebec, the specific inhalation challenge (SIC) test is
}

\section{Une comparaison des cas d'asthme exacerbés par le travail en situation clinique et épidémiologique}

HISTORIQUE : Les études cliniques et épidémiologiques font souvent appel à diverses définitions de cas dans différentes situations lorsqu'elles portent sur la même maladie (p. ex., l'asthme exacerbé par le travail [AET]). Ces différences sont susceptibles d'influer sur les caractéristiques des cas d'AET en résultant.

OBJECTIFS : Examiner cette question en comparant deux groupes de cas d'AET, l'un déterminé au moyen d'une évaluation clinique intensive et l'autre, d'après des critères épidémiologiques.

MÉTHODOLOGIE : Au total, 53 cas cliniques d'AET avaient été aiguillés vers deux cliniques de soins tertiaires du Canada en raison d'une présomption d'asthme professionnel. Les patients y avaient effectué des tests qui confirmaient l'asthme et écartaient l'asthme professionnel. Quarante-sept cas d'AET épidémiologiques étaient des patients asthmatiques occupant un emploi et traités dans une organisation de soins de santé intégrés des États-Unis qui avaient rempli un questionnaire et effectué une spirométrie et qui respectaient les critères d'AET en fonction d'une aggravation autodéclarée de l'asthme professionnel et d'une exposition pertinente en milieu de travail déterminée par un groupe d'experts.

RÉSULTATS : Le recours à divers critères de cas dans diverses situations donnait lieu à des groupes de cas comportant un mélange de similarités et de différences. Les cas d'AET cliniques étaient plus susceptibles d'avoir consulté au cabinet d'un médecin au moins trois fois pour l'asthme au cours de l'année précédente (75\% par rapport à $11 \%$; $<<0,0001$ ), mais ne s'associaient pas à un plus grand nombre d'urgences ou d'hospitalisations liées à l'asthme et n'avaient pas des valeurs spirométriques plus faibles. Les deux groupes différaient énormément selon l'industrie où évoluaient les cas et l'emploi qu'ils occupaient.

CONCLUSIONS : Il faudrait tenir compte des résultats des deux types d'études au moment de mesurer l'apport du travail dans les exacerbations de l'asthme, d'en déterminer les agents putatifs et de sélectionner les industries et les emplois où il faudrait implanter un dépistage et des programmes de surveillance.

routinely used to differentiate OA from WEA $(6,7)$. Asthma patients in Quebec with a strong temporal relationship between workplace exposures and symptomatic episodes are classified as OA if they have a positive SIC test and as WEA if they have a negative SIC test.

Epidemiological studies of WEA often rely on information collected by questionnaire to define a case and devote little or no attention to the results of objective clinical tests $(8-12)$. The relevant items on questionnaires commonly refer to respiratory symptoms that are worse at work or on work days, or that improve on days off work. Other epidemiological studies define WEA based on self-reported workrelated symptoms and relevant exposures at work (13), or work-related patterns of serial peak-expiratory flow values (14).

The manner in which WEA cases are identified, including the case definitions, can vary substantially between clinical and epidemiological settings. The recommendations issued by guidelines based on findings from epidemiological studies may not be applicable to clinical settings that use different definitions. A common assumption is that using more objective test-based criteria for WEA in a clinical setting rather than using criteria applied to questionnaire data in

${ }^{1}$ Division of Respiratory Disease Studies, National Institute for Occupational Safety and Health, Centers for Disease Control and Prevention,

Morgantown, West Virginia, USA; ${ }^{2}$ Hôpital du Sacré-Coeur de Montréal, Université de Montréal, Montreal, Quebec

Correspondence: Dr Catherine Lemière, Department of Chest Medicine, Hôpital du Sacré-Coeur de Montréal, 5400 Gouin Ouest, Montreal,

Quebec H4J 1C5. Telephone 514-338-2796, fax 514-338-3123, e-mail catherine.lemiere@umontreal.ca 
TABLE 1

Comparison of how work-exacerbated asthma (WEA) cases were identified in the clinical and epidemiological settings

\begin{tabular}{|c|c|c|}
\hline & Clinical cases & Epidemiological cases \\
\hline Source of cases & $\begin{array}{l}\text { Specialty clinic, with cases referred that had experienced } \\
\text { persistent problems with asthma symptoms related to work }\end{array}$ & $\begin{array}{l}\text { Working adults with asthma treated at a health maintenance organization } \\
\text { and not necessarily referred for any special evaluation }\end{array}$ \\
\hline Criteria for asthma & $\begin{array}{l}\text { Symptoms consistent with asthma, and also reversible airflow } \\
\text { obstruction or } \mathrm{PC}_{20}<8 \mathrm{mg} / \mathrm{mL}\end{array}$ & $\begin{array}{l}\text { Diagnosis of asthma in medical records, confirmed by self-report on } \\
\text { questionnaire }\end{array}$ \\
\hline Criteria for WEA & $\begin{array}{l}\text { Worsening of asthma symptoms when exposed at workplace } \\
\text { and a negative specific inhalation challenge }\end{array}$ & $\begin{array}{l}\text { Based on self-reported worsening of asthma associated with work and } \\
\text { judgement by expert panel that relevant exposures existed at work }\end{array}$ \\
\hline $\begin{array}{l}\text { Method for ruling out } \\
\text { occupational asthma }\end{array}$ & Could not be WEA if specific inhalation challenge was positive & $\begin{array}{l}\text { Asthma cases with onset during time period of interest } \\
\text { (past } 12 \text { months) were not considered to be at risk for WEA }\end{array}$ \\
\hline
\end{tabular}

$P C_{20}$ Provocative concentration of methacholine causing a $20 \%$ fall in forced expiratory volume in $1 \mathrm{~s}$

an epidemiological setting will yield different populations, with the clinical cases requiring more treatment and having worse indicators of respiratory health. In addition, the jobs and associated work exposures of cases may differ according to the setting and case definition.

We investigated the impact of setting and operational definition of WEA on the characteristics of the samples selected by comparing two sets of WEA cases (one from a clinical setting and one from an epidemiological study) to assess whether they differed with respect to asthma care, respiratory function and type of job. While neither sample was assembled initially with this goal in mind, the availability of similar data from all of the cases made it possible to pursue this comparison.

\section{METHODS}

WEA cases from a clinical setting

The clinical cases were recruited prospectively between November 2005 and November 2008 in Canada. They were part of a prospective cohort study from two Quebec tertiary clinics to which workers were referred for possible OA (R01 OH008391 from the Centers for Disease Control and Prevention, Georgia, USA) (15). The study was approved by the Quebec Ethics Committee. All participants signed an informed consent form before participating in the present study. Detailed medical and occupational questionnaires that collected information about respiratory symptoms at work, medication, smoking habits and work environment were completed. Pulmonary function tests were performed pre- and postmethacholine or bronchodilator inhalation. SIC was subsequently performed to differentiate OA from WEA.

The diagnosis of asthma was based on the presence of asthmarelated signs and symptoms, with either reversible airflow limitation or a provocative concentration of methacholine causing a $20 \%$ fall in forced expiratory volume in $1 \mathrm{~s}\left(\mathrm{FEV}_{1}\right)\left(\mathrm{PC}_{20}\right)<8 \mathrm{mg} / \mathrm{mL}$. Subjects who reported a worsening of their asthma symptoms when at work with a negative SIC were classified as WEA cases. To obtain relevant subject-specific information, an authorization was obtained from the Commission d'accès à l'information du Québec for linking the medical charts to the information provided by the Régie de l'assurance maladie $d u$ Québec (RAMQ) and MED-ECHO regarding the outpatient clinic visits, visits to the emergency department and hospitalizations during the year preceding and following the initial visit to the Quebec clinical centres. RAMQ is the provincial health insurance plan and MED$\mathrm{ECHO}$ is a provincial database that houses information regarding admissions to acute care hospitals.

\section{WEA cases from an epidemiological setting}

The other case group was selected from participants in an epidemiological study of WEA that was conducted by the National Institute for Occupational Safety and Health (NIOSH) in collaboration with a health maintenance organization (HMO) in Massachusetts (USA). Detailed methods for the study are published elsewhere (13). The NIOSH Human Subjects Review Board approved the present research and all participants provided informed consent. The HMO electronic medical records were scanned over a 16-month period (September 2000 to December 2001) to identify adults 18 to 44 years of age who had been enrolled in the HMO for at least six months, did not have a recorded diagnosis for any of several diseases (ie, congestive heart failure, bronchiectasis, emphysema, pulmonary embolism and pulmonary hypertension), and had current asthma as indicated by a diagnosis of asthma, use of asthma medications and having sought care for asthma in the past 12 months. In an effort to avoid selecting cases of chronic obstructive pulmonary disease and cardiac asthma during the electronic record search, patients $>44$ years of age were not included. Also excluded were asthma cases with other diseases to ensure that study findings were relevant to asthma and not due to confounding by another condition. After the computerized search, a research nurse conducted structured manual reviews of paper medical records to confirm evidence from the electronic records. Potential participants were contacted by telephone and invited to complete a telephone questionnaire. Anyone who had experienced their first asthma attack in the previous 14 months was excluded to ensure that any relationship of symptoms with work in the past 12 months was more likely to indicate work-related exacerbation rather than onset of asthma. During March 2001 through August 2002, 598 (61\%) of 978 individuals who were contacted completed the questionnaire. Brief interviews with the 380 nonparticipants revealed that they were similar in age and equally as likely to have moderate or severe asthma as those who participated, but were somewhat more likely to be male (ie, 44\% versus 31\%) (13). WEA status was based on having sufficient evidence from self-reports of WRA symptoms (ie, symptoms improved when away from work), medication use (ie, asthma medication use greater on work days) and asthma triggers in the previous 12 months, and the judgment by an expert panel that the individual was likely to have experienced exposures at work that could exacerbate asthma. The expert panel comprised an industrial hygienist and an epidemiologist who independently reviewed job descriptions reported on the questionnaire without knowledge of the participant's reports regarding WRA problems. Using these criteria, 136 (23\%) of 598 subjects were determined to have evidence of WEA in the previous 12 months.

In a subsequent study of participants who had completed the telephone interview, 382 who were still enrolled in the HMO and currently employed were invited to perform office and serial spirometry (14). Of the 178 (47\%) who completed office spirometry, 47 (26\%) fulfilled the survey criteria for WEA. Office spirometry was performed using a commericially available volume spirometer (OMI Sensormedics 922, SensorMedics, USA) calibrated according to American Thoracic Society standards (16). A detailed description of the procedures for performing spirometry appear elsewhere (14).

Identification of WEA cases in clinical and epidemiological settings Table 1 summarizes how the two types of WEA cases differed with regard to case sources, asthma criteria, criteria for WEA and how the researchers ruled out OA. The clinical cases had sought care for suspected WRA and been referred for specialized evaluation, while the epidemiological cases were identified among adults with asthma in a quasi-population-based setting (an HMO) and had not necessarily already reported work-related problems. The criteria for asthma and 
WEA used for clinical cases included more objective tests than those used for epidemiological cases. The results of SIC played a critical role in differentiating WEA (negative SIC) from OA (positive SIC) in the setting where clinical cases were diagnosed. In contrast, SIC was not used with any epidemiological cases, and WEA was separated from OA based on the timing of the onset of asthma symptoms (ie, those with onset of asthma in the past year were not at risk for WEA).

\section{Work histories}

Work histories were collected in both venues. The jobs held by clinical cases when they experienced WRA symptoms were compared with the jobs held by epidemiological cases during the 12 months before they completed the survey questionnaire. The same researcher coded industry and occupation for the jobs in both samples. The coding schemes used were the 2002 North American Industry Classification System (17) and the 2000 Standard Occupational Classification System (18).

\section{Criteria for airflow obstruction}

Cases from both sources were considered to be positive for airflow obstruction if, based on the prebronchodilator testing, the observed $\mathrm{FEV}_{1}$ and the ratio of the $\mathrm{FEV}_{1}$ and forced vital capacity (FVC) fell below their respective lower limits of normal (LLN) (19). All LLN values were calculated using reference values generated from spirometry data collected during the third National Health and Nutrition Examination Survey (NHANES III) (19).

\section{Outcomes of interest}

Asthma care and spirometry between the two types of WEA cases were compared. Accordingly, it was assessed whether one group was more likely to have frequent outpatient care for asthma (ie, $\geq 3$ office visits in the past 12 months), severe asthma-related events (ie, visited an emergency room or hospitalized for asthma in the previous 12 months) or decrements in spirometry (eg, $\mathrm{FEV}_{1}<\mathrm{LLN}$ and obstruction). Also compared were the types of industries and occupations in which the clinical and epidemiological cases worked.

\section{Analysis}

The Student's $t$ test was used for the analysis of crude continuous data. To test for statistical significance with categorical data, the continuitycorrected $\chi^{2}$ statistic or Fisher's exact test (if any expected cell count was $<5$ ) was used.

A least squares linear regression model was fit for the continuous outcome of per cent predicted $\mathrm{FEV}_{1}$. The dichotomous variables of interest were relatively common; therefore, the prevalence ratios were calculated rather than ORs $(20,21)$. This was accomplished using a Cox regression model with robust variance (22) and constant follow-up time for all (23).

The covariate for type of WEA case (ie, clinical versus epidemiological) was forced into each regression model. Several other variables common to both samples could possibly act as confounders. Covariates for potential confounders that were tested for inclusion in each regression model were: age (in years) at test, sex, former smoker and current smoker, body mass index (BMI $\left.\left[\mathrm{kg} / \mathrm{m}^{2}\right]\right)$ and number of years since asthma onset. Using backward stepwise elimination, any of these covariates with $\mathrm{P}<0.25$ was retained.

All statistical analyses were performed using SAS version 9.2 (SAS Institute Inc, USA). Unless stated otherwise, $\mathrm{P} \leq 0.05$ was considered to be statistically significant and $0.05<\mathrm{P} \leq 0.10$ was considered to be borderline significant.

\section{Descriptive characteristics}

\section{RESULTS}

Clinical cases were more likely to be male ( $57 \%$ versus $38 \%$; $\mathrm{P}=0.10$ ) and had a somewhat lower BMI (mean $28.2 \mathrm{~kg} / \mathrm{m}^{2}$ versus $30.6 \mathrm{~kg} / \mathrm{m}^{2}$; $\mathrm{P}=0.07$ ) than epidemiological cases (Table 2). Clinical cases had higher maximum and mean ages, which is consistent with the fact that they had no upper age limit, while epidemiological cases could not be
TABLE 2

Comparison of descriptive characteristics for clinical and epidemiological cases of work-exacerbated asthma

\begin{tabular}{|c|c|c|c|}
\hline \multirow[b]{2}{*}{ Characteristic } & \multicolumn{2}{|r|}{ Cases } & \multirow[b]{2}{*}{$P^{*}$} \\
\hline & Clinical & Epidemiological & \\
\hline $\mathrm{n}$ & 53 & 47 & NA \\
\hline Male & $30(57)$ & $18(38)$ & 0.10 \\
\hline Caucasian & $49(92)$ & $46(98)$ & 0.37 \\
\hline Body mass index, mean \pm SEM & $28.2 \pm 0.7$ & $30.6 \pm 1.1$ & 0.07 \\
\hline \multicolumn{4}{|l|}{ Age, years } \\
\hline Minimum, maximum & 19,61 & $21,46^{\dagger}$ & NA \\
\hline Mean \pm SEM & $42.5 \pm 1.6$ & $37.2 \pm 1.0$ & 0.006 \\
\hline \multicolumn{4}{|l|}{ Asthma onset } \\
\hline $\begin{array}{l}\text { Years since asthma onset, } \\
\text { mean } \pm \text { SEM }\end{array}$ & $7.1 \pm 1.5$ & $22.8 \pm 1.7$ & $<0.0001$ \\
\hline$>12$ years of age at onset & $46(88)$ & $23(49)$ & $<0.0001$ \\
\hline \multicolumn{4}{|l|}{ Smoking status } \\
\hline Never & $13(25)$ & $27(57)$ & Reference \\
\hline Former & $22(42)$ & $10(21)$ & 0.005 \\
\hline Current & $18(34)$ & $10(21)$ & 0.02 \\
\hline $\begin{array}{l}\text { Pack-years in ever smokers, } \\
\text { mean } \pm \text { SEM }\end{array}$ & $18.1 \pm 3.1$ & $14.2 \pm 2.9$ & 0.42 \\
\hline \multicolumn{4}{|l|}{ Conditions at home } \\
\hline Water damage at home & $8(15)$ & $8(17)$ & 1.0 \\
\hline Mouldy odour at home & $9(17)$ & $9(19)$ & 0.98 \\
\hline
\end{tabular}

Data presented as $n$ (\%) unless otherwise indicated. *Based on Student's $t$ test for continuous data, and continuity corrected $\chi^{2}$ or Fisher's exact test for categorical data; ${ }^{\dagger}$ The oldest participant was 44 years of age, by design, when first identified in the medical records as a potential participant, and 46 when tested. NA Not applicable

older than 44 years of age when first identified. Despite the older age of the clinical cases, they reported a mean of 7.1 years since first asthma symptoms, which was approximately one-third the comparable value for the epidemiological cases (22.8 years), and were much more likely to have experienced onset of symptoms at $\geq 12$ years of age. This could reflect, in part, the restriction that participants in the epidemiological study could not have experienced onset of asthma in the previous 12 months. The clinical cases were more likely to have ever smoked ( $75 \%$ versus $43 \%$ ) but the smokers in the two groups had similar pack-year values $(\mathrm{P}=0.42)$. The frequency of self-reported water damage and mouldy odour at home were similar in the two groups.

Distribution of jobs according to industry and occupation

The 53 clinical cases reported 57 jobs and the 47 epidemiological cases reported 56 jobs. The two types of WEA cases tended to work in different industries, with one-half of the clinical cases in one category and the epidemiological cases scattered among different industries. Specifically, 49\% ( $n=28)$ of current jobs reported by clinical cases were in manufacturing, compared with only $5 \%(n=3)$ of jobs held by epidemiological cases. The three most common industries for jobs among epidemiological cases were educational services (20\% [n=11]), health care and social assistance $(18 \%[n=10])$ and retail trade $(14 \%[n=8])$. The comparable percentages for clinical cases were considerably lower, with $2 \%(n=1), 9 \%(n=5)$ and $4 \%(n=2)$, respectively. Similar to the distribution according to industry, approximately one-half of the jobs for clinical WEA cases were in one major occupation category and the jobs for epidemiological cases were dispersed among several categories. The dominant occupation for clinical cases was production, with $47 \%$ $(n=27)$, while only $4 \%(n=2)$ of jobs for epidemiological cases were in this occupational category. The top three occupations for epidemiological cases were office and administrative support $(16 \%[n=9])$, health care practitioners and technical $(11 \%[\mathrm{n}=6])$, and sales and related $(11 \%$ $[\mathrm{n}=6])$. The distribution of jobs for clinical cases according to these three occupations was $4 \%(n=2), 4 \%(n=2)$ and $0 \%(n=0)$, respectively. 
TABLE 3

Asthma care and spirometry results for clinical and epidemiological cases of work-exacerbated asthma

\begin{tabular}{|c|c|c|c|}
\hline \multirow[b]{2}{*}{ Characteristic } & \multicolumn{2}{|c|}{ Cases } & \multirow[b]{2}{*}{$\mathbf{P}^{*}$} \\
\hline & $\begin{array}{c}\text { Clinical } \\
(n=53)\end{array}$ & $\begin{array}{c}\text { Epidemiological } \\
(n=47)\end{array}$ & \\
\hline \multicolumn{4}{|l|}{ Asthma care in past 12 months } \\
\hline$\geq 3$ visits to doctor's office & $40(75)$ & $5(11)$ & $<0.0001$ \\
\hline $\begin{array}{l}\text { Visited emergency room or } \\
\text { hospitalized }\end{array}$ & $9(17)$ & $7(15)$ & 0.99 \\
\hline \multicolumn{4}{|l|}{ Spirometry } \\
\hline $\mathrm{FEV}_{1}<\mathrm{LLN}$ & $24(45)$ & $17(36)$ & 0.36 \\
\hline FVC $<$ LLN & $10(19)$ & $9(19)$ & 1.0 \\
\hline $\mathrm{FEV}_{1} / \mathrm{FVC}<\mathrm{LLN}$ & $19(36)$ & $18(38)$ & 0.96 \\
\hline Airflow obstruction $^{\dagger}$ & $15(28)$ & $11(23)$ & 0.74 \\
\hline \multicolumn{4}{|c|}{$\%$ predicted spirometry, mean \pm SEM } \\
\hline $\mathrm{FEV}_{1}$ & $80.4 \pm 2.2$ & $84.7 \pm 2.3$ & 0.18 \\
\hline FVC & $89.9 \pm 1.8$ & $93.9 \pm 2.0$ & 0.15 \\
\hline $\mathrm{FEV}_{1} / \mathrm{FVC}$ & $89.5 \pm 1.6$ & $90.1 \pm 1.8$ & 0.78 \\
\hline
\end{tabular}

Data presented as $n(\%)$ unless otherwise indicated. *Based on continuity corrected $\chi^{2}$ or Fisher's exact test for $2 \times 2$ categorical data and Student's t test for continuous data; ${ }^{\dagger}$ Prebronchodilator forced expiratory volume in $1 \mathrm{~s}\left(F E V_{1}\right)$ and $F E V_{1}$ /forced vital capacity (FVC) ratio were both < lower limits of normal (LLN)

\section{Asthma care and spirometry according to type of WEA case}

Three-quarters of the clinical cases reported visiting a doctor's office for asthma care at least three times in the past year compared with only $11 \%$ of the epidemiological cases (Table 3 ). The two case types were approximately equally as likely to have visited an emergency room or stayed overnight in a hospital for asthma during the past year. The clinical cases had somewhat worse spirometry, as shown by the percentage of cases with $\mathrm{FEV}_{1}<\mathrm{LLN}$, and with the mean per cent predicted values for $\mathrm{FEV}_{1}$ and FVC (Table 3 ). However, these differences were not statistically significant. Statistical modelling confirmed what was observed with the crude data. Even after controlling for potential confounders, such as age and sex, WEA case type had no association with $\mathrm{FEV}_{1}<\mathrm{LLN}, \mathrm{FVC}<\mathrm{LLN}$, obstruction, per cent predicted $\mathrm{FEV}_{1}$ and per cent predicted FVC (models not shown). When the outcome was modelled based on either a visit to an emergency room or overnight stay in a hospital because of asthma, none of the potential confounders remained in the model (ie, all $\mathrm{P}>0.25$ ), and the findings for the crude data analyses (Table 3) are sufficient to conclude that this outcome did not differ according to type of WEA case. However, while controlling for age and BMI, the clinical cases were more likely to have sought asthma care at a doctor's office $\geq 3$ times in the past 12 months, with a prevalence ratio of 8.0 (95\% CI 3.6 to 18 ) (Table 4).

The difference in age ranges between the two groups (see Table 2) raised concern that comparisons between the two groups could be influenced by the 23 clinical cases who were $>46$ years of age, which was the age of the oldest epidemiological case. Therefore, the crude data analyses in Table 3 were repeated with all 47 members of the epidemiological group, but only the 30 members of the clinical group who were $\leq 46$ years of age (data not shown). This exercise confirmed the earlier results based on data from all 53 clinical cases. The main difference between the two case groups that is highlighted in Table 3 persisted: $80 \%(n=24)$ of the 30 clinical cases $\leq 46$ years of age had visited a doctor's office for asthma $\geq 3$ times in the past 12 months, compared with only $11 \%$ for the epidemiological cases $(P<0.0001)$. Statistical modelling with the reduced number of clinical cases yielded results similar to when all clinical cases were included (data not shown).
TABLE 4

Regression model for having at least three medical office visits for asthma in the past 12 months

\begin{tabular}{lcc}
\hline Covariate & Prevalence ratio (95\% Cl) & $\mathbf{P}$ \\
\hline Age at test, years & $0.99(0.97-1.00)$ & 0.11 \\
Body mass index & $1.02(0.99-1.06)$ & 0.22 \\
Type of work-exacerbated asthma & $8.0(3.6-18)$ & $<0.0001$ \\
case: 0=epidemiological, 1=clinical & & \\
\hline
\end{tabular}

\section{DISCUSSION}

Epidemiological and clinical studies of the same condition often differ in the case source and operational case definitions. The impact of these different methods has rarely been assessed. Our study was the first to compare the clinical and environmental characteristics of workers defined as having WEA according to contrasting clinical and epidemiological definitions. The main differences observed between the two types of cases in the current study relate to the number of visits to a physician for asthma, and the type of occupations and industries of the workers enrolled in the clinical and epidemiological studies.

The differences between the clinical and epidemiological cases were likely related to the different definitions of WEA and the referral processes. The epidemiological WEA cases were identified among adults with asthma in a quasi-population-based setting (an HMO) and had not necessarily previously reported experiencing work-related problems. In contrast, the clinical cases were identified from a referral population characterized by persistent problems with WRA symptoms and a suspicion of $\mathrm{OA}$. The diagnosis of $\mathrm{OA}$ is frequently suspected in workers who are exposed to known sensitizers (such as isocyanates) that are often found in the manufacturing industry. Those cases tend to be referred to the Quebec tertiary centres for further evaluation; however, $\mathrm{OA}$ is often subsequently ruled out by the performance of the SIC test, and the cases are diagnosed with WEA. This likely explains the differences observed in the distribution of workforces between the clinical cases from Quebec and epidemiological cases from Massachusetts. Indeed, those differences did not appear to be due to differences in the distribution of workforces in these two regions. Specifically considering the most common industry (ie, manufacturing) for clinical cases and the three most common industries for epidemiological cases, the labour force in Quebec (based on the 2006 census) was $14 \%$ manufacturing, $7 \%$ educational services, $11 \%$ health care and social assistance, and $12 \%$ retail trade. The comparable percentages in Massachusetts (based on the 2000 census) were $13 \%$ manufacturing, $5 \%$ educational services, $15 \%$ health care and social assistance, and $11 \%$ retail trade.

The differences in referrals may also explain the sex difference observed between the two types of WEA cases. Approximately onehalf of the clinical cases of WEA were employed in the manufacturing sector, in which males dominate the workforce. From the 2006 census in Quebec, 70\% of the manufacturing workforce was male, but the comparable figure was $50 \%$ in all other industries. Furthermore, some of the contrasts between the clinical and epidemiological WEA cases resembled differences previously noted between OA and WEA cases. From WRA cases identified from surveillance conducted in four states in the United States, $47 \%$ of the OA cases were male versus only $31 \%$ of WEA cases (24). In the current comparison, clinical WEA cases were $57 \%$ male, while epidemiological cases were $38 \%$ male. Furthermore, from surveillance data collected in the United States, $46 \%$ of OA cases worked in manufacturing, which was more than twice that for WEA cases (22\%) (24). The current comparison revealed that $49 \%$ of jobs among clinical WEA cases and only $5 \%$ of jobs among epidemiological cases were in the manufacturing industry.

The clinical WEA cases were more likely to be symptomatic and seek medical care, and reported more asthma-related visits to a doctor's office than the epidemiological cases. This difference was likely influenced by the inclusion criteria for clinical cases, which required 
subjects to seek medical care to be identified and enrolled into the study. Health care is organized differently in Canada and the United States, with access to care more consistent in the former. While we cannot entirely rule out the possibility that differences in the health care systems contributed to the current findings, the contrast in care seeking between the two groups is unlikely to be due to a difference in access to care because all of the epidemiological cases from Massachusetts benefited from health insurance, similar to the clinical cases from Quebec. The need by clinical cases for more care did not include emergency care and hospitalization (Table 3). This may have been be due to the fact that they received sufficient treatment in outpatient settings to minimize severe exacerbation episodes that would require emergency or inpatient care. It is also possible that although the clinical cases of WEA sought more medical attention than the epidemiological cases, the two groups may have experienced similar asthma severity given the similar number of severe asthma exacerbations and similar respiratory function findings.

The epidemiological cases were significantly more likely to have experienced asthma onset before 12 years of age (51\% versus $12 \%$ for clinical cases) and to have never smoked (57\% versus $25 \%$, respectively). These findings may be causally related, as suggested by a recent report that males with asthma onset in the first decade of life were less likely to start smoking during the second decade of life (25). This pattern is consistent with a 'healthy smoker' effect, which proposes that a person who initiates the habit must be healthy enough to resist some of the harmful effects of smoking (26).

Some asthma studies have identified that cases with recent onset versus chronic asthma are at greater risk for decrements in spirometry (27). The clinical cases were much closer to onset, with a mean of 7.1 years since first asthma symptoms compared with 22.8 years for the epidemiological cases. However, the current study found that the two types of WEA cases had similar spirometry values despite the clear difference in duration of asthma symptoms (Table 3). Interestingly, the findings suggest that the severity of asthma in WEA cases from the two sources was similar in spite of the fact that the clinical cases were referred to tertiary care facilities.

The current study had several limitations. The sample sizes were relatively small; therefore, there was limited power to discern statistically significant differences between the two types of cases. The two case samples were not collected with the goal of comparing them and not all types of information were collected in the same manner for both types of cases. For example, the two types of cases completed different asthma quality of life questionnaires, which prohibited comparisons. Looking ahead, this problem could be addressed by coordinating data collection prospectively rather than making comparisons based solely on existing data.

All of the epidemiological WEA cases experienced their first attack of asthma at least 14 months before being interviewed; however, the symptoms experienced in the year before interview may still have been indicative of work contributing to asthma onset rather than to a separate exacerbation episode. Seven (15\%) of the 47 epidemiological cases experienced onset of asthma while employed in the same job that they held when interviewed. One of the seven experienced onset 21 months before being interviewed, which meant that exacerbation events in the previous year could have been due to the same workplace conditions that contributed to asthma onset. The other six cases with the same job at interview as when their asthma started experienced onset five to 18 years earlier; therefore, the causes for onset and recent exacerbation were unlikely to be the same.

It is also important to understand that the current comparison involves WEA cases in only two settings, and many other criteria are used in both clinical and epidemiological studies. For example, in Ontario, clinical criteria for both WEA and OA are less dependent on the SIC test than in Quebec and closer to the criteria used by many clinicians in the United States. Differences in rules for compensating WEA could also lead to differences between case samples. For example, Ontario compensates WEA more readily than most jurisdictions in the United States, which means the motivation for diagnosis, the referral process for evaluation and the types of cases differ. Many epidemiological studies have relied on self-reported work-related symptoms among existing asthma cases to define WEA and have not considered workplace exposures in the case criteria $(9,10,28-30)$. However, it is likely that the referral process found in many clinical studies selects workers with suspected OA and exposed to sensitizers, whereas epidemiological studies are not subject to this influence. The variety of case criteria for WEA provides additional opportunities to compare WEA cases and better understand the implications of different methods for identifying cases.

The present study showed that despite very different selection criteria, the clinical and epidemiological WEA cases were very similar with respect to spirometry and the need for emergency or hospital care. However, the types of industries and occupations varied widely. This should be taken into account when the occupational exposures of workers with WEA are described in epidemiological and clinical cases. Findings from both types of studies should be considered when measuring the contribution of work to the burden of asthma exacerbations, identifying putative agents, and selecting industries and occupations in which to implement screening and surveillance programs. In future studies, coordination of data collected for WEA cases in different settings would contribute to a more in-depth understanding of similarities and differences between case groups than what was realized in the current study. Also, given the variety of industries and occupations in which WEA cases were observed, including jobs where OA cases may be uncommon, physicians should ask all employed asthma patients about the work-relatedness of their asthma symptoms $(1,2)$.

ACKNOWLEDGEMENTS: The authors thank Louis-Philippe Boulet, Michel Gérin, Denis Bégin and Amélie Forget who helped in the recruitment of a part of the study subjects and analysis of some of the clinical data in Quebec. Also, the authors thank the asthma patients who participated in the epidemiological study in the United States, and collaborators Donald Milton, Randy Boylstein, Susan Derk, Peggy Preusse, Richard Rosiello and Susan Sama, who helped with planning and implementing the original study.

AUTHORSHIP: PKH and CL made substantial contributions to research design; acquisition, analysis, and interpretation of the data; drafting and revising the paper; and approving the submitted version. XL made substantial contributions to the management and analysis of data; critically revising the paper; and approving the submitted version.

FUNDING: The recruitment of study subjects in Quebec was funded by Cooperative Agreement number R01 OH008391 from the Centers for Disease Control and Prevention (United States).

DISCLOSURES: The authors have no financial disclosueres or conflicts of interest to declare.

ETHICS APPROVAL: Ethics approval was provided by the Quebec Ethics Committee and the National Institute for Occupational Safety and Health Human Subjects Review Board.

DISCLAIMERS: The findings and conclusions in this report are those of the authors and do not necessarily represent the views of the National Institute for Occupational Safety and Health (NIOSH). Mention of a specific product or company does not constitute endorsement by NIOSH. 


\section{REFERENCES}

1. Tarlo SM, Balmes J, Balkissoon R, et al. Diagnosis and management of work-related asthma: American College of Chest Physicians consensus statement. Chest 2008;134:1S-41S.

2. Henneberger PK, Redlich CA, Callahan DB, et al. An official American Thoracic Society statement: Work-exacerbated asthma Am J Respir Crit Care Med 2011;184:368-78.

3. Balmes J, Becklake M, Blanc P, et al. American Thoracic Society statement: Occupational contribution to the burden of airway disease. Am J Respir Crit Care Med 2003;167:787-97.

4. Tarlo SM, Leung K, Broder I, Silverman F, Holness DL. Asthmatic subjects symptomatically worse at work: Prevalence and characterization among a general asthma clinic population. Chest 2000;118:1309-14.

5. Wheeler S, Rosenstock L, Barnhart S. A case series of 71 patients referred to a hospital-based occupational and environmental medicine clinic for occupational asthma. West J Med 1998;168:98-104.

6. Larbanois A, Jamart J, Delwiche JP, Vandenplas O. Socioeconomic outcome of subjects experiencing asthma symptoms at work. Eur Respir J 2002;19:1107-13.

7. Lemiere C, Forget A, Dufour MH, Boulet LP, Blais L. Characteristics and medical resource use of asthmatic subjects with and without work-related asthma. J Allergy Clin Immunol 2007;120:1354-9.

8. Caldeira RD, Bettiol H, Barbieri MA, Terra-Filho J, Garcia CA, Vianna EO. Prevalence and risk factors for work related asthma in young adults. Occup Environ Med 2006;63:694-9.

9. Johnson AR, Dimich-Ward HD, Manfreda J, et al. Occupational asthma in adults in six canadian communities. Am J Respir Crit Care Med 2000;162:2058-62.

10. Johnson A, Toelle BG, Yates D, Belousova E, Ng K, Corbett S, Marks G. Occupational asthma in New South Wales (NSW): A population-based study. Occup Med (Lond) 2006;56:258-62.

11. Mehlum IS, Kjuus H, Veiersted KB, Wergeland E. Self-reported work-related health problems from the Oslo health study. Occup Med Oxf 2006;56:371-9.

12. Saarinen K, Karjalainen A, Martikainen R, et al. Prevalence of work-aggravated symptoms in clinically established asthma. Eur Respir J 2003;22:305-9.

13. Henneberger PK, Derk SJ, Sama SR, et al. The frequency of workplace exacerbation among health maintenance organisation members with asthma. Occup Environ Med 2006;63:551-7.

14. Bolen AR, Henneberger PK, Liang X, et al. The validation of work-related self-reported asthma exacerbation. Occup Environ Med 2007;64:343-8.
15. Chiry S, Boulet L-P, Lepage J, et al. Frequency of work-related respiratory symptoms in workers without asthma. Am J Industr Med 2009; $52: 447-54$.

16. ATS. Standardization of spirometry - 1994 update. Am J Respir Crit Care Med 1995;152:1107-36.

17. OMB. North American industry classification system, United States, 2002. Springfield: National Technical Information Service, 2002.

18. Commerce Dept US. Standard occupational classification system, 2000. Springfield: National Technical Information Service, 2000.

19. Hankinson JL, Odencrantz JR, Fedan KB. Spirometric reference values from a sample of the general us population. Am J Respir Crit Care Med 1999;159:179-87.

20. Lee J, Tan CS, Chia KS. A practical guide for multivariate analysis of dichotomous outcomes. Ann Acad Med Singapore 2009;38:714-9.

21. Thompson ML, Myers JE, Kriebel D. Prevalence odds ratio or prevalence ratio in the analysis of cross sectional data: What is to be done! Occup Environ Med 1998;55:272-7.

22. Lin DY, Wei LJ. The robust inference for the proportional hazards model. J Am Statist Assoc 1989;84:1074-8.

23. Barros AJ, Hirakata VN. Alternatives for logistic regression in cross-sectional studies: An empirical comparison of models that directly estimate the prevalence ratio. BMC Med Res Methodol 2003;3.

24. Goe SK, Henneberger PK, Reilly MJ, et al. A descriptive study of work aggravated asthma. Occup Environ Med 2004;61:512-7.

25. Verlato G, Bortolami O, Accordini S, et al. Asthma in childhood reduces smoking initiation in subsequent teens among males. J Adoles Health 2011;48:253-8.

26. Becklake MR, Lalloo U. The healthy smoker - a phenomenon of health selection. Respiration 1990;57:137-44.

27. Ulrik CS, Lange P. Decline of lung-function in adults with bronchial asthma. Am J Respir Crit Care Med 1994;150:629-34.

28. Abramson MJ, Kutin JJ, Rosier MJ, Bowes G. Morbidity, medication and trigger factors in a community sample of adults with asthma. Med J Aust 1995;162:78-81.

29. Henneberger PK, Deprez RD, Asdigian N, Oliver LC, Derk S, Goe SK. Workplace exacerbation of asthma symptoms: Findings from a population-based study in maine. Arch Environ Health 2003;58:781-8.

30. Henneberger PK, Hoffman CD, Magid DJ, Lyons EE. Work-related exacerbation of asthma. Int J Occup Environ Health 2002;8:291-6. 


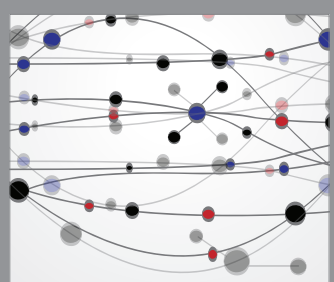

The Scientific World Journal
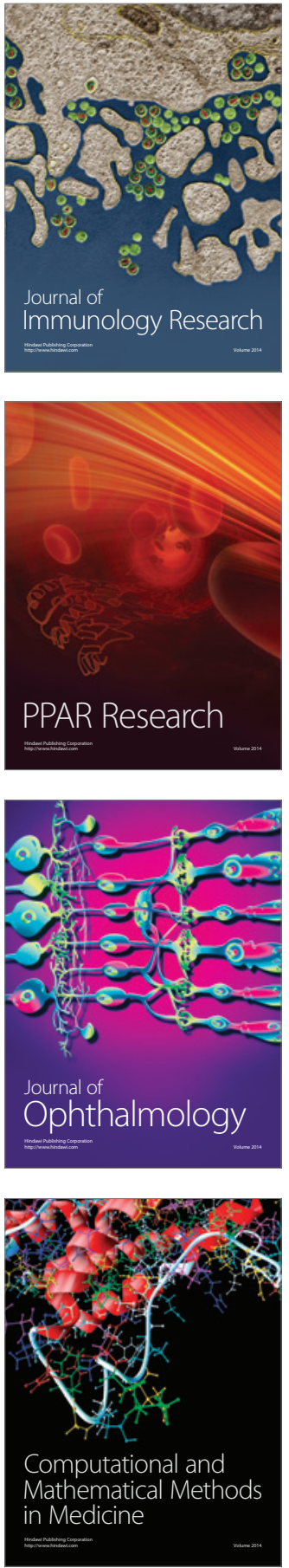

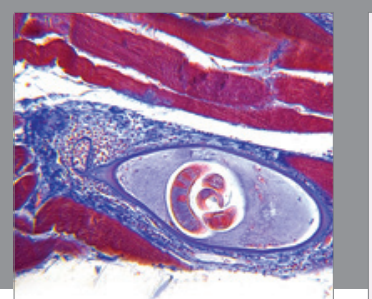

Gastroenterology Research and Practice

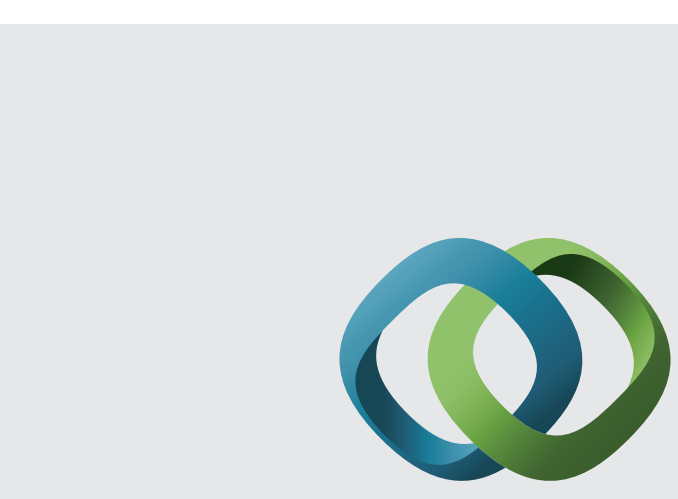

\section{Hindawi}

Submit your manuscripts at

http://www.hindawi.com
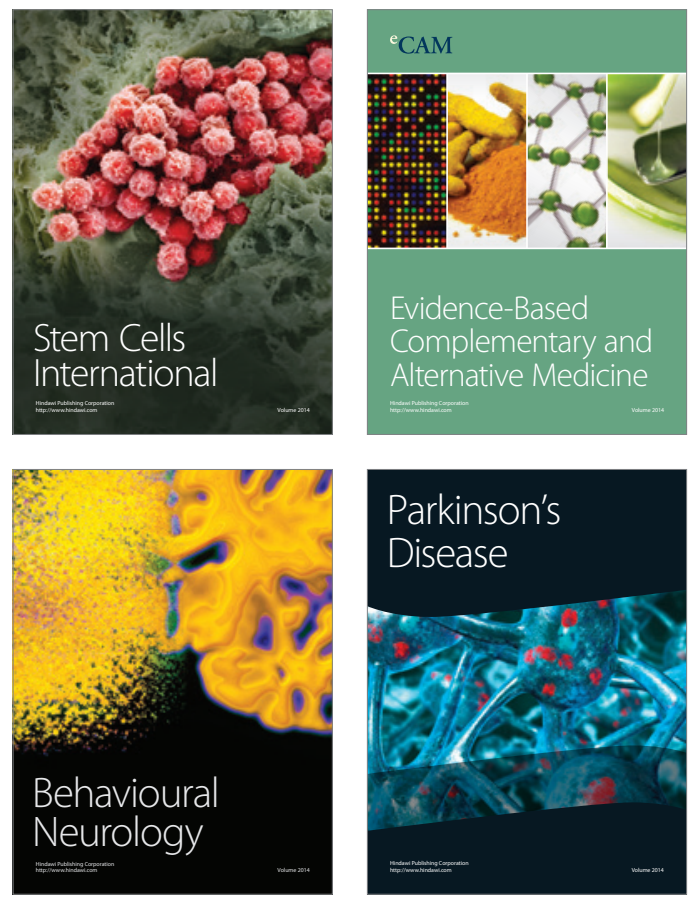
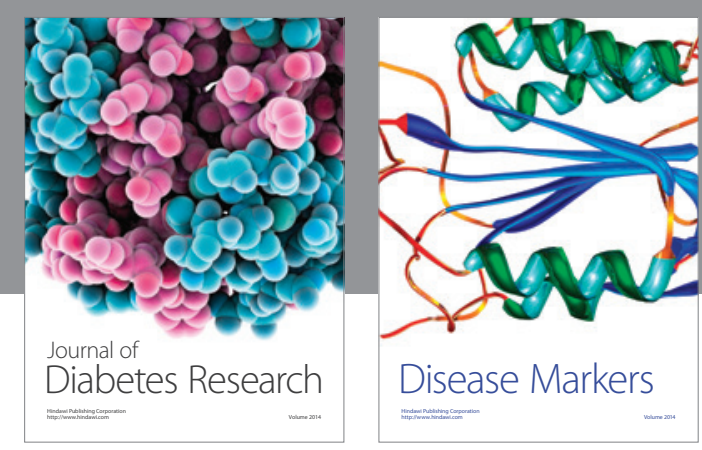

Disease Markers
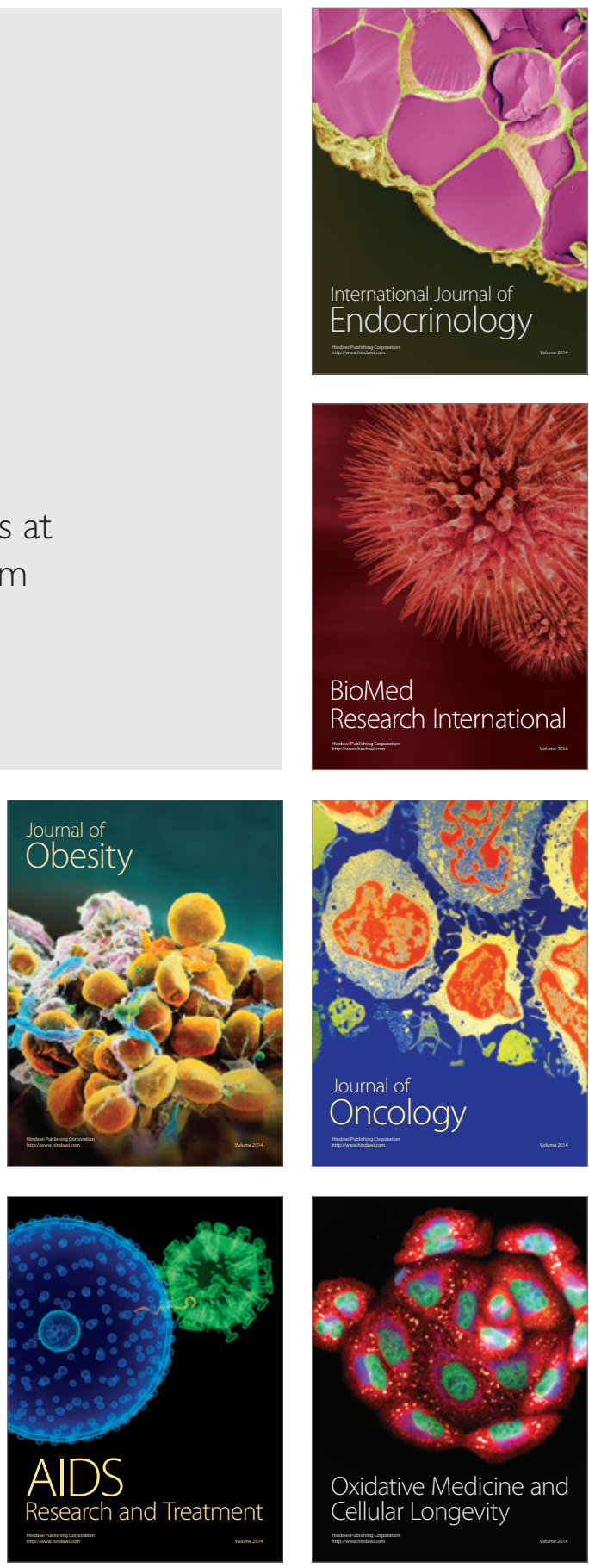